\title{
BMJ open The paternal role in pre-eclampsia and giving birth to a small for gestational age infant; a population-based cohort study
}

\author{
Anna-Karin Wikström, ${ }^{1,2}$ Jóhanna Gunnarsdóttir, ${ }^{2}$ Sven Cnattingius ${ }^{1}$
}

To cite: Wikström A-K, Gunnarsdóttir J,

Cnattingius S. The paternal role in pre-eclampsia and giving birth to a small for gestational age infant; a population-based cohort study. BMJ Open 2012;2:e001178. doi:10.1136/bmjopen-2012001178

- Prepublication history for this paper are available online. To view these files please visit the journal online (http://dx.doi.org/10.1136/ bmjopen-2012-01178).

Received 20 March 2012 Accepted 23 July 2012

This final article is available for use under the terms of the Creative Commons Attribution Non-Commercial 2.0 Licence; see http://bmjopen.bmj.com

\begin{abstract}
Objective: To estimate the effect of partner change on risks of pre-eclampsia and giving birth to a small for gestational age infant.

Design: Prospective population study.

Setting: Sweden.

Participants: Women with their first and second successive singleton births in Sweden between 1990 and 2006 without pregestational diabetes and/or hypertension ( $n=446459)$.

Outcome measures: Preterm ( $<37$ weeks) and term ( $\geq 37$ weeks) pre-eclampsia, and giving birth to a small for gestational age (SGA) infant. Risks were adjusted for interpregnancy interval, maternal age, body mass index, height and smoking habits in second pregnancy, years of involuntary childlessness before second pregnancy, mother's country of birth, years of formal education and year of birth. Further, when we calculated risks of SGA we restricted the study population to women with non-pre-eclamptic pregnancies.
\end{abstract}

Results: In women who had a preterm pre-eclampsia in first pregnancy, partner change was associated with a strong protective effect for preterm pre-eclampsia recurrence (OR 0.24; 95\% Cl 0.07 to 0.88). Similarly, partner change was also associated with a protective effect of recurrence of SGA birth (OR 0.75; $95 \% \mathrm{Cl}$ 0.67 to 0.84 ). In contrast, among women without SGA in first birth, partner change was associated with an increased risk of SGA in second pregnancy. Risks of term pre-eclampsia were not affected by partner change.

Conclusions: There is a paternal effect on risks of preterm pre-eclampsia and giving birth to an SGA infant.

${ }^{1}$ Department of Medicine, Clinical Epidemiology Unit at Karolinska Institutet, Stockholm, Sweden 2Department of Women's and Children's Health, Uppsala University, Uppsala, Sweden

\section{Correspondence to}

Dr Anna-Karin Wikström; anna-karin.wikstrom@kbh. uu.se

\section{INTRODUCTION}

Abnormal placentation is associated with preeclampsia, especially pre-eclampsia with an early onset, and with intrauterine growth restriction. ${ }^{1-3}$ In abnormal placentation, the trophoblast invasion of the decidua and myometrium is restricted. For successful

\section{ARTICLE SUMMARY}

Article focus

- Preterm pre-eclampsia and giving birth to a small for gestational age (SGA) are pregnancy disorders associated with abnormal placentation.

- The paternal role in placentation is debated and the focus of this article was therefore to estimate effect of partner change on risks of term and preterm pre-eclampsia and birth of an SGA infant in women with or without corresponding complication in prior pregnancy.

\section{Key messages}

- Partner change decreases recurrence risks of preterm pre-eclampsia and giving birth to an SGA infant in second pregnancy.

- In women who have not given birth to an SGA infant in their first delivery, partner change increase the risk of an SGA birth in the subsequent delivery.

- There is a paternal influence on placentation, where some partners seem less favourable for successful placentation.

Strengths and limitations of this study

- A major strength of the present study is the nationwide population-based design with a very small proportion of unidentified fathers (around 1\%), although some misclassification of paternity, as in all studies based on self-reported information of fatherhood, is expected. The prospective data collection precludes recall bias. The size of the study population enabled us to separate preterm from term pre-eclampsia and to analyse risk of SGA after excluding pre-eclamptic pregnancies. Although we had the opportunity to account for several important possible confounders that were not controlled for in earlier studies, we were not able to control for previous semen exposure, abortions and miscarriages or paternal characteristics.

placentation, tolerance against partner alloantigens is necessary and trophoblast invasion appears to be primarily controlled by immune mechanisms. ${ }^{4}$ Results from epidemiological studies suggest that some 
partners could be less favourable when it comes to successful placentation. ${ }^{5-7}$

On the basis of the partner-specific hypothesis, a change of partner could be protective for a recurrence of pregnancy disorders associated with abnormal placentation. Women with previously normal pregnancy could on the contrary increase their risk of a placental dysfunction disorder with partner change in the next pregnancy. Results from previous studies suggest that pre-eclampsia and fetal growth restriction have a fetal genetic component, and thus can be inherited on the paternal side. ${ }^{7-9}$ Thus, both immunological and genetic factors contributed by the father may be of importance for abnormal placentation.

Previous studies have failed to show a protective effect of partner change for recurrence of pre-eclampsia. ${ }^{10-12}$ Studies on the effect of partner change on risks of preeclampsia and intrauterine growth restriction in women without prior corresponding complication have yielded diverging results. ${ }^{10-18}$ Reasons for this could be failure to separate out diseases associated with abnormal placentation, and that most earlier studies in this field lack control of important confounders. ${ }^{10-12}$ 14-18

We conducted a nationwide Swedish study and included a cohort of 446000 women with their first and second births during the years 1990-2006 with available information on important factors influencing pregnancy outcomes. We estimated the effect of partner change on risks of term ( $\geq 37$ weeks) and preterm ( $<37$ weeks) preeclampsia in the second pregnancy as well as giving birth to an infant small for gestational age, in women with or without corresponding complication in their first pregnancy.

\section{MATERIAL AND METHOD}

The Swedish Medical Birth Register, held by the Swedish National Board of Health and Welfare, contains data on more than $98 \%$ of all births in Sweden since 1973, including demographic data, information on reproductive history and complications during pregnancy, delivery and the neonatal period. ${ }^{19}$ In Sweden antenatal care is standardised and free of charge. During the first antenatal visit, usually taking place at the end of the first trimes$\mathrm{ter}^{20}$ the mother is interviewed about her medical and obstetric history, including height, weight, smoking habits and years of involuntary childlessness before current pregnancy. Complications during pregnancy and delivery are classified according to the International Classification of Diseases (ICD) as noted by the responsible doctor at discharge from hospital. Information on each pregnancy and delivery is forwarded to the Birth Register through copies of standardised antenatal, obstetric and paediatric records. Individual record linkage between the Birth Register and other registers was possible through each individual's unique personal registration number, assigned to each Swedish resident. ${ }^{21}$ Information on the infant's father from the first and second live births was collected through linkage to the Multigeneration Register, and information about fathers to stillbirths was (when available) collected through the Stillbirth Register, also held by Statistics Sweden. Information on the mothers' country of birth and highest level of formal education was obtained by individual linkage with the Register of Total Population and the Education Register (31 December 2005).

\section{Study population}

During the years 1990-2006, there were approximately 1.6 million births recorded in the Birth Register. During this period, there were in all 452256 women with their first and second consecutive singleton pregnancies resulting in a birth at 22 weeks gestation or later. We excluded 5797 women with essential hypertension or pre-pregnancy diabetes mellitus as noted in first or second pregnancy. These women were identified at the first antenatal visit (using check-boxes) and/or at the discharge from hospital after the delivery (using diagnostic codes for essential hypertension (ICD-9 codes 642A-C; ICD-10 codes O10-11 and I10-15). Thereafter, the study population included 446459 women (table 1). We further excluded pregnancies with missing information on the father in first pregnancies $(n=4206 ; 0.9 \%)$ or second pregnancies $(\mathrm{n}=1931 ; 0.4 \%)$ and the final study population included 440322 women.

\section{Main exposure variable}

Our main exposure variable was change of partner between pregnancies. The personal registration number of the first infant's father was compared with that of the second infant's father. Paternity was categorised into same partner in the two pregnancies and changed partner between the two pregnancies.

\section{Outcomes in second pregnancy}

Pre-eclampsia was defined through ICD-9 and ICD-10 codes 642E-G and O14-15, respectively. Pre-eclampsia was categorised into term (gestational age 37 weeks or more at birth) and preterm (gestational age less than 37 weeks at birth). In Sweden, gestational age is assessed by ultrasound scans in $97 \%$ of women, usually around the 17 th week of gestation. ${ }^{22}$ If no early second trimester ultrasound scan was available, the last menstrual period was used to calculate gestational age at delivery. The clinical definition of pre-eclampsia during these years was a rise in blood pressure $(\geq 140 / 90)$ combined with proteinuria $(\geq 0.3 \mathrm{~g} / 24 \mathrm{~h})$. The quality of the diagnosis of pre-eclampsia has been validated previously: of 148 pregnancies coded as pre-eclampsia in the Birth Register, 137 (93\%) had the disease according to the individual records. ${ }^{23}$ When calculating risks of preeclampsia we included stillbirths, since stillbirth can be a degree of severity of the pre-eclampsia disease. During these years, stillbirth was defined as fetal death at 28 weeks of gestation or later. However, there is a poor reporting of fathers to stillbirths: information on fathers 
Table 1 Rates of pregnancy complications in second pregnancy by maternal characteristics

\section{Adverse outcomes second pregnancy}

\section{Pre-eclampsia}

\begin{tabular}{|c|c|c|c|c|c|c|c|}
\hline \multirow{3}{*}{ Maternal characteristics } & \multirow[b]{3}{*}{ Total number } & & \multirow{2}{*}{\multicolumn{2}{|c|}{$\begin{array}{l}\text { Small for gestational } \\
\text { age * }\end{array}$}} \\
\hline & & \multicolumn{2}{|c|}{ Term (<37 weeks) } & \multicolumn{2}{|c|}{ Preterm (<37 weeks) } & & \\
\hline & & Number & Rate (\%) & Number & Rate (\%) & Number & Rate (\%) \\
\hline \multicolumn{8}{|l|}{ Partner } \\
\hline Same & 409922 & 4779 & 1.17 & 958 & 0.23 & 22984 & 5.9 \\
\hline Different & 30400 & 417 & 1.37 & 133 & 0.44 & 2348 & 8.2 \\
\hline Data missing & 6137 & 105 & 1.71 & 33 & 0.54 & 389 & 9.3 \\
\hline \multicolumn{8}{|l|}{ Year of first birth } \\
\hline 1990-1994 & 187733 & 2224 & 1.18 & 384 & 0.20 & 11869 & 6.7 \\
\hline 1995-1999 & 137445 & 1760 & 1.28 & 438 & 0.32 & 7904 & 6.2 \\
\hline 2000-2006 & 121281 & 1317 & 1.09 & 302 & 0.25 & 5948 & 5.2 \\
\hline \multicolumn{8}{|c|}{ Interpregnancy interval (years) } \\
\hline$<1$ & 84268 & 753 & 0.89 & 110 & 0.13 & 4914 & 6.2 \\
\hline $1-3.9$ & 305769 & 3614 & 1.18 & 698 & 0.23 & 16799 & 5.8 \\
\hline $4-6.9$ & 41681 & 675 & 1.62 & 207 & 0.50 & 2837 & 7.3 \\
\hline $7-9.9$ & 10773 & 166 & 1.54 & 77 & 0.71 & 821 & 8.1 \\
\hline$\geq 10$ & 3727 & 87 & 2.33 & 30 & 0.80 & 325 & 9.3 \\
\hline Data missing & 241 & 6 & 2.49 & 2 & 0.83 & 25 & 14.0 \\
\hline \multicolumn{8}{|c|}{ Age second pregnancy (years) } \\
\hline$<25$ & 60195 & 585 & 0.97 & 109 & 0.18 & 4342 & 7.7 \\
\hline $25-29.9$ & 165336 & 1872 & 1.13 & 332 & 0.20 & 9152 & 5.9 \\
\hline 30-34.9 & 160041 & 1942 & 1.21 & 457 & 0.29 & 8601 & 5.7 \\
\hline$\geq 35$ & 60887 & 902 & 1.48 & 226 & 0.37 & 3626 & 6.4 \\
\hline \multicolumn{8}{|c|}{ Body mass index second pregnancy $\left(\mathrm{kg} / \mathrm{m}^{2}\right)$} \\
\hline$<18.5$ & 9655 & 48 & 0.50 & 18 & 0.19 & 1284 & 13.9 \\
\hline $18.5-24.9$ & 242986 & 1915 & 0.79 & 476 & 0.20 & 15032 & 6.5 \\
\hline$\geq 25$ & 125646 & 2569 & 2.04 & 444 & 0.35 & 5354 & 4.6 \\
\hline Data missing & 68172 & 767 & 1.13 & 186 & 0.27 & 4051 & 6.3 \\
\hline \multicolumn{8}{|l|}{ Height $(\mathrm{cm})$} \\
\hline$<162$ & 88848 & 1134 & 1.28 & 301 & 0.34 & 8184 & 9.9 \\
\hline $162-171$ & 253815 & 3003 & 1.18 & 615 & 0.24 & 13653 & 5.7 \\
\hline$\geq 172$ & 94122 & 1063 & 1.13 & 186 & 0.20 & 3213 & 3.6 \\
\hline Data missing & 9674 & 101 & 1.10 & 22 & 0.23 & 671 & 7.3 \\
\hline \multicolumn{8}{|c|}{ Smoking habits second pregnancy } \\
\hline Non-smoker & 375372 & 4646 & 1.24 & 924 & 0.25 & 18766 & 5.3 \\
\hline Smoker & 45091 & 354 & 0.79 & 77 & 0.17 & 5491 & 12.8 \\
\hline Data missing & 25996 & 301 & 1.16 & 123 & 0.47 & 1464 & 6.0 \\
\hline \multicolumn{8}{|c|}{ Involuntary childlessness second pregnancy (years) } \\
\hline$<1$ & 427908 & 4958 & 1.16 & 1025 & 0.24 & 24615 & 6.1 \\
\hline $1-2$ & 12080 & 209 & 1.73 & 48 & 0.40 & 728 & 6.5 \\
\hline$\geq 3$ & 5441 & 121 & 2.22 & 38 & 0.70 & 378 & 7.6 \\
\hline Data missing & 1030 & 13 & 1.26 & 13 & 1.26 & 0 & \\
\hline \multicolumn{8}{|l|}{ Mother's country of birth } \\
\hline Nordic & 394349 & 4903 & 1.24 & 981 & 0.25 & 20875 & 5.6 \\
\hline Non-Nordic & 48097 & 370 & 0.77 & 129 & 0.27 & 4442 & 9.7 \\
\hline Data missing & 4013 & 28 & 0.70 & 14 & 0.35 & 404 & 10.5 \\
\hline \multicolumn{8}{|l|}{ Education (years) } \\
\hline$<13$ & 130901 & 1809 & 1.38 & 342 & 0.26 & 8951 & 7.3 \\
\hline $13-14$ & 177302 & 2171 & 1.22 & 449 & 0.25 & 8903 & 5.4 \\
\hline$\geq 15$ & 102759 & 1064 & 1.04 & 237 & 0.23 & 4577 & 4.7 \\
\hline Data missing & 35497 & 257 & 0.72 & 96 & 0.27 & 3290 & 9.8 \\
\hline Total & 446459 & 5301 & 1.19 & 1124 & 0.25 & 25721 & 6.1 \\
\hline
\end{tabular}

was available in 574 of $1698(34 \%)$ stillbirths in first pregnancy and in 467 of $1030(45 \%)$ of stillbirths in second pregnancy.
Being born small for gestational age (SGA) was used as a proxy for intrauterine growth restriction and was defined as a birth weight at or below the 10th percentile for the 
mean birth weight for gestational age according to the sexspecific Swedish fetal growth curve. ${ }^{24}$ When analysing risks of SGA infant we only included live births. Giving birth to an SGA infant is associated with pre-eclampsia, and in the analyses of SGA we therefore excluded women with preeclampsia in first or second pregnancy. We further excluded 4655 pregnancies with missing information on infant's birth weight at first or second birth. The total population when calculating risks of SGA at second delivery included 420089 women (table 1), among whom information on partners from both childbirths was available in 415922 women (table 2).

\section{Covariates}

We calculated interpregnancy interval as the number of completed years between birth of the first infant and the estimated date of conception of the second infant. Information on maternal body mass index (BMI), height, smoking habits and years of involuntary childlessness before the pregnancy was collected from the first antenatal visit in second pregnancy, and data on maternal age were collected at second birth. Categorisations were made according to table 1 .

Mother's country of birth was categorised into born in a Nordic country (Sweden, Norway, Denmark, Finland or Iceland) and born in a non-Nordic country, and years of formal education were categorised into three levels according to table 1 .

\section{Statistics}

The effects of partner change of risks of term and preterm pre-eclampsia and giving birth to an SGA infant in a second pregnancy were calculated for both women with and without corresponding pregnancy complication in a first pregnancy. OR with $95 \%$ CI were estimated by unconditional logistic regression analysis after adjustments for maternal characteristics. When we calculated risks of SGA infant in second pregnancy we only included live births and pregnancies with pre-eclampsia were excluded. Adjustments were made for maternal factors associated with risks of pre-eclampsia and SGA, including interpregnancy interval, maternal age, BMI, height and smoking habits in second pregnancy, years of involuntary childlessness before second pregnancy, maternal country of birth and years of formal education. Further, we adjusted for year of second birth, categorised into before 1997 and 1997 or later.

We hypothesised that the impact of partner change on risk of disorders associated with abnormal placentation may depend on the presence of corresponding complication in prior pregnancy. We therefore performed interaction analyses between pre-eclampsia in first pregnancy (in three categories: no pre-eclampsia/term preeclampsia/preterm pre-eclampsia) and partner change (same vs different partner) on risks of term and preterm pre-eclampsia in the second pregnancy. Further, we performed an interaction analysis between SGA in first pregnancy (no/yes) and partner change on risk of SGA in a second pregnancy. All analyses were performed using the Statistical Analysis Software V.9.1 (SAS Institute Inc, Cary, North Carolina, USA).

\section{Ethics committee approval}

The study was approved by one of the Regional Ethical Review Boards in Stockholm, Sweden. Reference number: 2011/2:2. Date of approval: 3 March 2011. The board did not require the women to provide informed consent.

\section{RESULTS}

The overall rates of term ( $\geq 37$ weeks) and preterm (<37 weeks) pre-eclampsia in first pregnancy were $2.8 \%$ and $0.47 \%$, respectively, whereas $12.1 \%$ gave birth to an SGA infant. The corresponding rates in second pregnancy were about half as large as in first pregnancy (term pre-eclampsia $1.2 \%$, preterm pre-eclampsia $0.25 \%$ and SGA $6.1 \%$ ).

In table 1 we notice that rates of pre-eclampsia and SGA in second pregnancy were affected by maternal characteristics. The rates of pre-eclampsia in second pregnancy increased with interpregnancy interval, maternal age, BMI and years of involuntary childlessness before second pregnancy. Smoking was associated with reduced rates of pre-eclampsia, and women born in non-Nordic countries had a lower rate of term pre-eclampsia, compared to those born in Nordic countries. The rates of SGA in second pregnancy were inversely related to maternal height and BMI. Smokers had higher SGA rates than non-smokers, and the rates of SGA increased with years of involuntary childlessness before second pregnancy, longer interpregnancy interval and lower education.

Table 2 displays rates of pregnancy complications in second pregnancy and maternal characteristics by partner change between pregnancies. Compared to women who did not change partners, women who changed partners had higher rates of term and preterm pre-eclampsia and of SGA. Further, women who changed partners had longer interpregnancy intervals, were more often smokers, younger than 25 years or older than 35 years and they were slightly more often overweight $(\mathrm{BMI} \geq 25)$. Finally, compared to women who did not change partners, women who changed partner had slightly more often at least 1 year of involuntary childlessness before pregnancy, were lower educated (less than 13 years) and were less often born in a non-Nordic country.

As previous Scandinavian studies have reported a decreased risk of pre-eclampsia (term and preterm) after partner change in second pregnancy in women without pre-eclampsia in first pregnancy, ${ }^{10} 1217$ we reanalysed our dataset and controlled only for the same categorised variables as previous studies (interpregnancy interval, maternal age and year of birth). ${ }^{12}{ }^{17}$ In this analysis, we also found a reduced risk of pre-eclampsia after partner change (OR $0.85 ; 95 \%$ CI 0.76 to 0.96 ). To investigate whether this reduction in risk could be 
Table 2 Partner change between pregnancies by second pregnancy complications and maternal characteristics

\begin{tabular}{|c|c|c|c|}
\hline & \multirow[b]{2}{*}{ Number } & \multicolumn{2}{|l|}{ Partner } \\
\hline & & $\begin{array}{l}\text { Same } \\
\text { Rate (\%) }\end{array}$ & $\begin{array}{l}\text { Different } \\
\text { Rate (\%) }\end{array}$ \\
\hline \multicolumn{4}{|l|}{ Second pregnancy complications } \\
\hline Term (>37 weeks) pre-eclampsia & 5196 & 1.17 & 1.37 \\
\hline Preterm (<37 weeks) pre-eclampsia & 1091 & 0.23 & 0.44 \\
\hline SGA† & 25322 & 5.9 & 8.2 \\
\hline \multicolumn{4}{|l|}{ Maternal characteristics } \\
\hline \multicolumn{4}{|l|}{ Year of first birth } \\
\hline 1990-94 & 184949 & 40.9 & 57.1 \\
\hline 1995-99 & 135594 & 30.7 & 32.5 \\
\hline 2000-06 & 119779 & 28.4 & 10.4 \\
\hline \multicolumn{4}{|l|}{ Interpregnancy interval (years)* } \\
\hline$<1$ & 82500 & 20 & 2.3 \\
\hline $1-3.9$ & 302760 & 71.6 & 31 \\
\hline $4-6.9$ & 40848 & 7.2 & 37 \\
\hline $7-9.9$ & 10453 & 1 & 20.5 \\
\hline$>10$ & 3567 & 0.2 & 9.2 \\
\hline Data missing & 194 & & \\
\hline \multicolumn{4}{|l|}{ Age second delivery (years)* } \\
\hline$<25$ & 58938 & 12.9 & 19.7 \\
\hline $25-29.9$ & 163269 & 37.2 & 35.8 \\
\hline $30-34.9$ & 158168 & 36.4 & 29.4 \\
\hline$>35$ & 59947 & 13.5 & 15 \\
\hline \multicolumn{4}{|l|}{ Body mass index second pregnancy* } \\
\hline$<18.5$ & 9519 & 2.2 & 2.2 \\
\hline $18.5-24.9$ & 240089 & 54.7 & 52.4 \\
\hline$>25$ & 123731 & 27.9 & 30.8 \\
\hline Data missing & 66983 & 15.3 & 14.6 \\
\hline \multicolumn{4}{|l|}{ Height $(\mathrm{cm})^{\star}$} \\
\hline$<162$ & 87443 & 19.7 & 21.6 \\
\hline $162-171$ & 250495 & 56.9 & 57.2 \\
\hline$>172$ & 92890 & 21.1 & 19.4 \\
\hline Data missing & 9494 & 2.2 & 1.8 \\
\hline \multicolumn{4}{|l|}{ Smoking habits second pregnancy* } \\
\hline Non-smoker & 370797 & 85.6 & 65.7 \\
\hline Smoker & 43965 & 8.6 & 28.2 \\
\hline Data missing & 25560 & 5.8 & 6.1 \\
\hline \multicolumn{4}{|c|}{ Involuntary childlessness second pregnancy (years) ${ }^{\star}$} \\
\hline$<1 \quad$ & 422561 & 96 & 94.9 \\
\hline $1-2$ & 11943 & 2.7 & 3.4 \\
\hline$>3$ & 5351 & 1.2 & 1.7 \\
\hline Data missing & 467 & 0 & 0 \\
\hline \multicolumn{4}{|l|}{ Mother's country of birth* } \\
\hline Nordic & 389279 & 88.2 & 91.8 \\
\hline Non-Nordic & 47213 & 10.9 & 7.7 \\
\hline Data missing & 3830 & 0.9 & 0.5 \\
\hline \multicolumn{4}{|l|}{ Education (years) ${ }^{*}$} \\
\hline$<13$ & 128533 & 27.5 & 52.5 \\
\hline $13-14$ & 175222 & 40.2 & 33.8 \\
\hline$>15$ & 101778 & 24.1 & 10.1 \\
\hline Data missing & 34789 & 8.2 & 3.6 \\
\hline Total & 440322 & $409922(93.1 \%)$ & $30400(6.9 \%)$ \\
\hline
\end{tabular}


Table 3 Risks of term ( $\geq 37$ weeks) and preterm ( $<37$ weeks) pre-eclampsia in a second pregnancy by change of partner between pregnancies

\begin{tabular}{|c|c|c|c|c|c|}
\hline \multirow[b]{3}{*}{ Pre-eclampsia in first pregnancy } & \multicolumn{5}{|c|}{ Pre-eclampsia in second pregnancy } \\
\hline & \multirow[b]{2}{*}{ Number } & \multirow[b]{2}{*}{ Rates (\%) } & \multicolumn{3}{|l|}{ OR $(95 \% \mathrm{Cl})$} \\
\hline & & & Crude & Adjusted* & Fully adjusted $\dagger$ \\
\hline \multicolumn{6}{|l|}{ No } \\
\hline Same partner & 3362 & 0.85 & Reference & Reference & Reference \\
\hline Different partner & 340 & 1.15 & $1.36(1.22$ to 1.52$)$ & $0.86(0.75-0.98)$ & $0.97(0.84-1.14)$ \\
\hline Different partner & 67 & 9.19 & $0.92(0.71-1.20)$ & $0.98(0.73-1.31)$ & $1.03(0.74-1.44)$ \\
\hline \multicolumn{6}{|l|}{ Preterm } \\
\hline Same partner & 275 & 14.20 & Reference & Reference & Reference \\
\hline Different partner & 10 & 8.26 & $0.54(0.28-1.05)$ & $0.72(0.36-1.47)$ & $0.82(0.37-1.80)$ \\
\hline \multicolumn{6}{|l|}{ Preterm } \\
\hline Same partner & 149 & 1.29 & Reference & Reference & Reference \\
\hline Different partner & 14 & 1.92 & $1.50(0.86-2.61)$ & $0.80(0.42-1.53)$ & $0.92(0.43-1.96)$ \\
\hline \multicolumn{6}{|l|}{ Preterm } \\
\hline Same partner & 140 & 7.23 & Reference & Reference & Reference \\
\hline Different partner & 6 & 4.96 & $0.67(0.29-1.55)$ & $0.42(0.16-1.06)$ & $0.24(0.07-0.88)$ \\
\hline
\end{tabular}

attributable to other factors that differed between women who changed and did not change partners, other variables were added to this model. When we only added smoking or BMI, corresponding ORs were no longer significantly reduced (OR 0.93 ; $95 \%$ CI 0.82 to 1.05 ; and OR $0.95 ; 95 \%$ CI 0.83 to 1.08 , respectively). Finally, when we controlled for all confounders (BMI, height, smoking habits, year of involuntary childlessness, maternal country of birth and years of formal education), we found no effect of partner change on risk of pre-eclampsia (OR 0.97; 95\% CI 0.85 to 1.11 ; results not shown in table).

We found significant interactions between history of pre-eclampsia and partner change on risks of preterm and term pre-eclampsia in a second pregnancy $(\mathrm{p}<0.001$, respectively). Further, we also found significant interactions between history of SGA and partner change on risk of SGA in a second pregnancy $(\mathrm{p}<0.001)$. Analyses of the effects of partner change on risks of pre-eclampsia (term and preterm) and SGA in second pregnancy were therefore stratified by presence or absence of corresponding complication in first pregnancy.

Table 3 displays rates and risks of term and preterm pre-eclampsia in second pregnancy in women with or without corresponding complication in first pregnancy by partner change between pregnancies. In women without pre-eclampsia in first pregnancy, unadjusted risks of term and preterm pre-eclampsia in second pregnancy were higher in women who changed partner between pregnancies than in women who did not. In adjusted analyses, partner change did not increase the risk of term pre-eclampsia, but there was a weak tendency of increased risk of preterm pre-eclampsia in the fully adjusted model.

In women who had a term pre-eclampsia in first pregnancy, partner change did not influence risks of term or preterm pre-eclampsia (table 3 ). However, in women who had preterm pre-eclampsia in first pregnancy, partner change was strongly protective for recurrence of preterm pre-eclampsia, but there was no significant protective effect of partner change on risk of term pre-eclampsia.

Table 4 displays risks of giving birth to an SGA infant in a second non-pre-eclamptic pregnancy by partner change between pregnancies. Among women who did not give birth to an SGA infant in first pregnancy, partner change was associated with a slightly increased risk of SGA infant in second pregnancy also in the fully adjusted model. In women whose first birth was a SGA birth, partner change was protective for a second SGA birth.

\section{DISCUSSION}

The findings in this study support a paternal influence on placentation. Women who in their first pregnancy had preterm pre-eclampsia or an SGA infant decreased their risks for recurrence of the disorder if they changed 
Table 4 Risks of giving birth to an infant small for gestational age (SGA) infant in second pregnancy by change of partner between pregnancies, when excluding first and second pregnancies with pre-eclampsia

\section{SGA in second pregnancy}

\begin{tabular}{|c|c|c|c|c|c|}
\hline \multirow[b]{3}{*}{ SGA in first pregnancy } & \multirow[b]{3}{*}{ Number } & \multirow[b]{3}{*}{ Rates (\%) } & \multirow{2}{*}{\multicolumn{3}{|c|}{ OR (95\% Cl) }} \\
\hline & & & & & \\
\hline & & & Crude & Adjusted* & Fully adjusted $†$ \\
\hline \multicolumn{6}{|l|}{ No } \\
\hline Same partner & 13556 & 4 & Reference & Reference & Reference \\
\hline Different partner & 1539 & 6.2 & 1.60 (1.52 to 1.69$)$ & $1.44(1.35$ to 1.54$)$ & 1.15 (1.07 to 1.24$)$ \\
\hline \multicolumn{6}{|l|}{ Yes } \\
\hline Same partner & 9428 & 20.4 & Reference & Reference & Reference \\
\hline Different partner & 809 & 20.1 & $0.98(0.91$ to 1.06$)$ & $0.89(0.81$ to 0.98$)$ & 0.75 (0.67 to 0.84$)$ \\
\hline
\end{tabular}

*Adjusted for interpregnancy interval.

†Fully adjusted model. Adjustments were made for interpregnancy interval, maternal age, early pregnancy body mass index, height and smoking habits in second pregnancy, years of involuntary childlessness before second pregnancy, mother's country of birth and years of formal education and the year of second birth.

partner. Further, women who did not give birth to an SGA infant at their first delivery slightly increased their risk of an SGA birth at their second delivery if they changed partner between pregnancies.

A major strength of the present study is the nationwide population-based design with a very small proportion of unidentified fathers (around 1\%), although some misclassification of paternity, as in all studies based on selfreported information of fatherhood, is expected. The prospective data collection precludes recall bias. The size of the study population enabled us to separate preterm from term pre-eclampsia and to analyse risk of SGA after excluding pre-eclamptic pregnancies. As information on BMI was available from 1992 onwards, we choose to restrict our study population to women with their two first single births between 1990 and 2006. This restriction resulted in a low number of recurrent preterm pre-eclampsia, especially in the group of women who changed partners between pregnancies. However, the same restriction also resulted in that we only used ICD-9 and ICD-10 codes when defining pre-eclampsia, which is a strength compared to earlier Scandinavian studies. ${ }^{1012} 17$ Although we had the opportunity to account for several important possible confounders that were not controlled for in earlier studies, we cannot exclude that our findings partly are results of unmeasured confounding. We were not able to control for previous semen exposure, abortions and miscarriages, although this might be partially controlled for with interpregnancy interval and involuntary childlessness. Another limitation is that we did not have information on paternal characteristics, such as birth weight, height and BMI which could confound at least the SGA results. ${ }^{25}$

Results from several epidemiological studies suggest that some fathers might be less genetically favourable when it comes to successful placentation, sometimes referred to as the dangerous father hypothesis. ${ }^{26}$ The risk of pre-eclampsia has been shown to be higher in pregnancies fathered by men who themselves are born in a pre-eclamptic pregnancy ${ }^{5} 7$ or who previously fathered a pre-eclamptic pregnancy in another woman. ${ }^{6}$ Other studies suggest that priming against partner- specific antigens is important for tolerance induction, the primipaternity hypothesis. ${ }^{4} 26$ There are reports of increased pre-eclampsia and SGA risks in primigravidas with short duration of sperm exposure from her partner before pregnancy, ${ }^{27} 28$ an increased risk of pre-eclampsia in pregnancies conceived via donator insemination ${ }^{29}$ and a partner-specific protection from pre-eclampsia after abortion. ${ }^{14}$ Further, most of the early studies on pre-eclampsia risk in multiparas report an increased risk of the disorder after partner change. ${ }^{11} 15 \quad 16$ However, women who change partners between pregnancies generally have longer interpregnancy intervals than women who do not change partners and risk of pre-eclampsia increases with length of interpregnancy interval. Three large Scandinavian cohort studies report, after controlling for interpregnancy interval (maternal age and year of birth), a decreased risk of pre-eclampsia after partner change in women without prior pre-eclampsia. ${ }^{10} \quad 12 \quad 17$ Results from our study confirm and extend on these findings. When we controlled for the same variables as previous studies, ${ }^{12}{ }^{17}$ we found a reduced risk of preeclampsia after partner change. Interpregnancy interval may reflect different underlying factors in women with and without partner change. For example, among women who do not change partners, long interpregnancy intervals are more common among women with chronic diseases and subfertile women. ${ }^{30}$ In our investigation, we found that women who changed partners differed from women who did not change partners with respect to all studied risk factors, including maternal education, BMI and notably smoking. When we adjusted for such variables, we found no association between partner change and risk of pre-eclampsia in women without prior pre-eclampsia, suggesting that previous studies suffer from residual confounding.

In our analyses of risks of SGA, we expanded our analyses on effect of partner change on risks associated with abnormal placentation in second pregnancy. Similar to the findings of pre-eclampsia, we found that partner change reduced the recurrence risk of SGA. In addition, among women with no previous SGA birth, partner 
change increased the risk of SGA, supporting the hypothesis that partner change increases the risk of a placental dysfunction disorder in women with a prior normal pregnancy. The non-significant association between partner change and risk of preterm pre-eclampsia in women with a first normal pregnancy could be an effect of the lower prevalence of preterm pre-eclampsia.

In this study we report a novel finding of protection from recurrence of pregnancy disorders associated with abnormal placentation after a change of partner. Women with preterm pre-eclampsia or SGA infant in their first pregnancy decreased their risk of recurrence of the disorder in next pregnancy if they had changed partners. Abnormal placentation has a stronger association to preterm than term pre-eclampsia, ${ }^{3} 3132$ and earlier studies have probably failed to show this association since they have not separated preterm from term pre-eclampsia. ${ }^{10-17}$ We have only found one earlier study of SGA recurrence after partner change and this study could not show a protective effect of partner change. ${ }^{18}$ This study was of a much smaller sample size than our study and did not control for several important confounders.

We found the highest rates of abnormal placental disorders in parous women who also had the disorder in first pregnancy, independent if they changed partner between pregnancies. This indicates that maternal factors have the major impact on successful placentation. Our findings especially support the 'dangerous father' hypothesis. ${ }^{26}$ How the father exerts this effect is unknown, but a genetic effect is likely. Trophoblast cells are shown to express various receptors capable of immune modulation and even spiral artery remodelling. ${ }^{33}$ Paternal genetic polymorfism in receptors or transmitters involved in immune regulation or vascular remodelling might be involved in placentation and in adverse pregnancy outcomes associated with abnormal placentation. ${ }^{26}$ 33-35 Paternal-specific human lymphocyte antigen-C is expressed by trophoblast, interact with maternal uterine natural killer cells, and a mismatch in the couple-specific interaction can lead to a susceptibility to abnormal placentation. ${ }^{35}$ There might also be a paternal effect on placentation through variation in composition of the seminal fluid. Seminal fluid might have an immunomodulatory role in the uterus, probably through high levels of transforming growth factor $\beta$ and probably also other cytokines. ${ }^{36}$

In conclusion, our findings indicate that there is a paternal effect in the development of placental dysfunction disorders.

Contributors A-KW had the original idea to the study. All authors contributed to the design of the study. A-KW performed the analyses and wrote the first draft of the manuscript. All authors made substantial contribution to the interpretation of results and manuscript revision. Further, they had full access to all of the data in the study and can take responsibility for the integrity of the data and the accuracy of the data analysis.

Funding The study was supported by the European Union's Seventh Framework Programme (FP7/2007-2011) under grant agreement 259679, Swedish Society of Medicine (project No. 101291) and Karolinska Institutet (Distinguished Professor Award 2011).The researchers are independent from the funders.

\section{Competing interests None.}

Provenance and peer review Not commissioned; externally peer reviewed.

Data sharing statement No additional data are available.

\section{REFERENCES}

1. Brosens IA, Robertson WB, Dixon HG. The role of the spiral arteries in the pathogenesis of preeclampsia. Obstet Gynecol Annu 1972;1:177-91.

2. Brosens I, Dixon HG, Robertson WB. Fetal growth retardation and the arteries of the placental bed. Br J Obstet Gynaecol 1977;84:656-63.

3. Egbor M, Ansari T, Morris N, et al. Morphometric placental villous and vascular abnormalities in early- and late-onset pre-eclampsia with and without fetal growth restriction. BJOG 2006;113:580-9.

4. Redman CW, Sargent IL. Immunology of pre-eclampsia. Am J Reprod Immunol 2010;63:534-43.

5. Esplin MS, Fausett MB, Fraser A, et al. Paternal and maternal components of the predisposition to preeclampsia. N Engl J Med 2001;344:867-72.

6. Lie RT, Rasmussen $\mathrm{S}$, Brunborg $\mathrm{H}$, et al. Fetal and maternal contributions to risk of pre-eclampsia: population based study. BMJ 1998;316:1343-7.

7. Skjaerven R, Vatten LJ, Wilcox AJ, et al. Recurrence of pre-eclampsia across generations: exploring fetal and maternal genetic components in a population based cohort. BMJ 2005;331:877

8. Cnattingius S, Reilly M, Pawitan Y, et al. Maternal and fetal genetic factors account for most of familial aggregation of preeclampsia: a population-based Swedish cohort study. Am J Med Genet A 2004;130A:365-71.

9. Svensson $\mathrm{AC}$, Pawitan $\mathrm{Y}$, Cnattingius $\mathrm{S}$, et al. Familial aggregation of small-for-gestational-age births: the importance of fetal genetic effects. Am J Obstet Gynecol 2006;194:475-9.

10. Basso O, Christensen K, Olsen J. Higher risk of pre-eclampsia after change of partner. An effect of longer interpregnancy intervals? Epidemiology 2001;12:624-9.

11. Li DK, Wi S. Changing paternity and the risk of preeclampsia/ eclampsia in the subsequent pregnancy. Am J Epidemiol 2000;151:57-62.

12. Trogstad $\mathrm{LI}$, Eskild $\mathrm{A}$, Magnus $\mathrm{P}$, et al. Changing paternity and time since last pregnancy; the impact on pre-eclampsia risk. A study of 547238 women with and without previous pre-eclampsia. Int $J$ Epidemiol 2001;30:1317-22.

13. Mostello D, Kallogjeri D, Tungsiripat R, et al. Recurrence of preeclampsia: effects of gestational age at delivery of the first pregnancy, body mass index, paternity, and interval between births. Am J Obstet Gynecol 2008;199:55e1-7.

14. Saftlas AF, Levine RJ, Klebanoff MA, et al. Abortion, changed paternity, and risk of preeclampsia in nulliparous women. $A m J$ Epidemiol 2003;157:1108-14.

15. Feeney JG, Scott JS. Pre-eclampsia and changed paternity. Eur J Obstet Gynecol Reprod Biol 1980;11:35-8.

16. Tubbergen P, Lachmeijer AM, Althuisius SM, et al. Change in paternity: a risk factor for preeclampsia in multiparous women? J Reprod Immunol 1999;45:81-8.

17. Skjaerven R, Wilcox AJ, Lie RT. The interval between pregnancies and the risk of preeclampsia. N Engl J Med 2002;346:33-8.

18. Krulewitch CJ, Herman AA, Yu KF, et al. Does changing paternity contribute to the risk of intrauterine growth retardation? Paediatr Perinat Epidemiol 1997;11(Suppl 1):41-7.

19. Cnattingius S, Ericson A, Gunnarskog J, et al. A quality study of a medical birth registry. Scand J Soc Med 1990;18:143-8.

20. Lindmark G, Cnattingius $\mathrm{S}$. The scientific basis of antenatal care. Report from a state-of-the-art conference. Acta Obstet Gynecol Scand 1991;70:105-9.

21. Ludvigsson JF, Otterblad-Olausson P, Pettersson BU, et al. The Swedish personal identity number: possibilities and pitfalls in healthcare and medical research. Eur J Epidemiol 2009;24:659-67.

22. SBU. Routine ultrasound examination during pregnancy. Stockholm, Sweden: Swedish Council on Technology Assessment in Health Care (SBU), 1998. Report No.: 139.

23. Ros HS, Cnattingius S, Lipworth L. Comparison of risk factors for preeclampsia and gestational hypertension in a population-based cohort study. Am J Epidemiol 1998;147:1062-70.

24. Marsal K, Persson PH, Larsen T, et al. Intrauterine growth curves based on ultrasonically estimated foetal weights. Acta Paediatr 1996;85:843-8. 
25. Shah PS. Paternal factors and low birthweight, preterm, and small for gestational age births: a systematic review. Am J Obstet Gynecol 2010;202:103-23.

26. Dekker G, Robillard PY, Roberts C. The etiology of preeclampsia: the role of the father. J Reprod Immunol 2011;89:126-32.

27. Einarsson JI, Sangi-Haghpeykar H, Gardner MO. Sperm exposure and development of preeclampsia. Am J Obstet Gynecol 2003; 188:1241-3.

28. Kho EM, McCowan LM, North RA, et al. Duration of sexual relationship and its effect on preeclampsia and small for gestational age perinatal outcome. J Reprod Immunol 2009;82:66-73.

29. Need JA, Bell B, Meffin E, et al. Pre-eclampsia in pregnancies from donor inseminations. J Reprod Immunol 1983;5:329-38.

30. Zhang J. Partner change, birth interval and risk of pre-eclampsia: a paradoxical triangle. Paediatr Perinat Epidemiol 2007;21(Suppl 1): 31-5.

31. Odegard RA, Vatten LJ, Nilsen ST, et al. Preeclampsia and fetal growth. Obstet Gynecol 2000;96:950-5.
32. Aardema MW, Saro MC, Lander M, et al. Second trimester Doppler ultrasound screening of the uterine arteries differentiates between subsequent normal and poor outcomes of hypertensive pregnancy: two different pathophysiological entities? Clin Sci (Lond) 2004:106:377-82.

33. Riley JK. Trophoblast immune receptors in maternal-fetal tolerance. Immunol Invest 2008;37:395-426.

34. Prusac IK, Zekic Tomas S, Roje D. Apoptosis, proliferation and Fas ligand expression in placental trophoblast from pregnancies complicated by HELLP syndrome or pre-eclampsia. Acta Obstet Gynecol Scand 2011;90:1157-63.

35. Hiby SE, Walker JJ, O'Shaughnessy KM, et al. Combinations of maternal KIR and fetal HLA-C genes influence the risk of preeclampsia and reproductive success. J Exp Med 2004:200:957-65.

36. Robillard PY, Dekker G, Chaouat G, et al. Epidemiological studies on primipaternity and immunology in preeclampsia-a statement after twelve years of workshops. J Reprod Immunol 2011;89:104-17. 